\title{
A Prospective Audit of Blood Transfusion Reactions in Tertiary Care Hospital for the Use of Blood and Blood Components
}

Venkatachalapathy TS*

Senior Resident (Work Done at Puducherry), Indira Gandhi Govt General Hospital and Post Graduate Institute, Puducherry

\begin{abstract}
Aims and Background: Like any other drug, therapeutic use of blood and its components has its own side effects, adverse reactions and risks involved. Overall use of blood has been on the increase in most tertiary care hospitals. Since the guidelines for blood and its components use in a clinical setting are well defined, but not practiced in reality, the present study aims at defining the problems associated with blood transfusion in the light of its risks and benefits as a drug.
\end{abstract}

Materials and Methods: We carried out prospective survey of 1453 units of blood and components for 696 patients during period of 6 months and recorded the indications for usage and transfusion reactions associated with its usage.

Results: Out of 1453 units' blood/blood component transfused, $48(3.30 \%)$ units of blood developed transfusion reactions. Of these, 41 were produced by whole blood, $(85.41 \%) \& 5$ units $(10.42 \%)$ by packed cells. FFP 1 unit $(2.08 \%)$ for a patient with alcoholic liver disease produced reaction. 1 unit of fresh whole blood $(2.08 \%)$ has produced reaction. Medical cases produced the more number of blood transfusion reactions (14 patients). Most of the blood transfusion reactions were allergic $(50 \%)$ and most of the reactions were produced after multiple transfusions.

Conclusion: There is lack of blood transfusion committee in IGGGH\&PGI, Puducherry Hospital, which has produced inappropriate transfusions due to absence of strict transfusion triggers.

Transfusion Trigger: $\mathrm{Hb} \%<7 \mathrm{gms} \%$ is an indication for blood transfusion and hematocrit $<27 \%$ is an indication. Blood transfusion should be started immediately after its issue from blood bank, if not used within $1 / 2$ hour and then replaces it to blood bank for cold chain maintenance.

Transfusion reactions (3.3\%) more common agent is whole blood, since it contains all unnecessary components, which produces allo- immunization.

Blood component usage should be increased which will reduce the incidence of transfusion reaction.

Keywords: Transfusion reaction; Whole blood; Febrile reaction

\section{Introduction}

There is no substitute, which has all the properties of human blood. The idea of blood transfusion appeared in the $15^{\text {th }}$ and $16^{\text {th }}$ centuries with the belief that the transfusion of the blood from a young and healthy person into an aged or debilitated individual would restore youth and health. In 1628, William Harvey gave the theory of circulation of blood. The first documented experimental blood transfusion in dogs was performed by Richard Lower in middle of $17^{\text {th }}$ century [1].

It was James Blundell in $18^{\text {th }}$ century who along with Dr. Leacock concluded after experimentation that only humans should serve as the source of human blood transfusion. Blundell, the father of modern obstetrics performed about 10 transfusions on women dying of postpartum hemorrhage [2].

In 1901 Karl Landsteiner discovered the ABO blood group system and thus laid the foundation of modern blood transfusion. It was A. Hustin and L. Agote in 1914 who first discovered that citrate could be used as anti-coagulant for red cells. J. Loutit and P. Mollison in 1943 developed acid citrate dextrose solution for red cells storage [3].

During the last decade the scenario of transfusion medicine has changed significantly. The use of whole blood has been almost restricted to neonatal exchange transfusion. Emphasis is given on the use of specific blood components for appropriate and rational use of blood. Although various blood substitutes have been developed, but as yet prior to the discovery of blood group antigens, approximately one third of human transfusions resulted in adverse outcome, often death [4]. With the discovery of blood group antigens in 1901, by Karl Landsteiner, transfusion therapy changed from a hazardous proposition to a relatively safe procedure. Safety from transfusion transmitted diseases improved with advancement of technology. The recent testing facilities have lowered the incidence of transfusion-transmitted diseases to minimum [5]; however, the incidence of adverse events due to human errors [6], ABO incompatibility, alloimmunization, bacterial contamination and immunomodulation phenomena remain a matter of concern.

\section{Methodology}

Permission was obtained from medical superintendent for

*Corresponding author: Dr. Venkatachalapathy TS, Devaraj URS Medical College, Tamaka, Kolar, Karnataka, India, Tel: +918197507094; E-mail: drvenkey@hotmail.com

Received December 24, 2011; Accepted March 16, 2012; Published March 22 2012

Citation: Venkatachalapathy TS (2012) A Prospective Audit of Blood Transfusion Reactions in Tertiary Care Hospital for the Use of Blood and Blood Components. J Blood Disord Transfus 3:118. doi:10.4172/2155-9864.1000118

Copyright: (c) 2012 Venkatachalapathy TS. This is an open-access article distributed under the terms of the Creative Commons Attribution License, which permits unrestricted use, distribution, and reproduction in any medium, provided the original author and source are credited. 
Citation: Venkatachalapathy TS (2012) A Prospective Audit of Blood Transfusion Reactions in Tertiary Care Hospital for the Use of Blood and Blood Components. J Blood Disord Transfus 3:118. doi:10.4172/2155-9864.1000118

conducting the study and collecting information from case sheets. The questionnaire has been designed in such a way that it is applicable to both surgical and non-surgical patients undertaking blood transfusion in all departments of the Indira Gandhi Govt General Hospital and post graduate institute (IGGGH \& PGI). The complete details of the study were not disclosed to clinicians to prevent bias during study.

In IGGGH\&PGI Hospital blood transfusion is done depending on the transfusion triggers decided in the particular departments (in specific individual units).

A total of 1453 units of blood/blood components transfused to 696 patients were analyzed (10/09/2010 to 09/03/2011). The data obtained from the questionnaire showed blood/blood components were obtained from IGGGH\&PGI Hospital Blood Bank. An average of 8.07 units of blood were transfused per day, at an average of 2.08 units of blood/ blood components was transfused/patient during the study period.

696 cases have been classified as patients in Medical \& Surgical wards. Under the Department of Surgery patients from General Surgery, orthopedics and OBG were included. All cases in all departments have been analyzed individually.

The single case in the Department of Psychiatry had been treated for moderate anemia $(\mathrm{Hb}-7.6 \%)$ with one unit of whole blood.

Cases in NICU \& Pediatrics also have been analyzed individually.

Transfusion triggers for blood transfusion being stipulated in individual units in particular departments depending on,

- History.

- Clinical Symptoms and signs.

- Laboratory investigations (Complete Haemogram).

Cold chain maintenance for blood and blood products was explained to the staff nurses [7], if the blood was not used within $1 / 2$ hour after its issue, then it had to be sent back to the blood bank for its storage. No storage of blood should be done in outside wards, to prevent occurrence of blood transfusion reaction. Personal observation of about 200 blood/blood component transfusions was monitored and significance of not warming of blood prior to transfusion was explained to the staff nurses.

\section{Analysis}

Out of 696 patients, 324 (46.55\%) patients received a single unit of blood for which the main indication was history of anemia (mild) in medical cases or depending on the intraoperative blood loss in surgical patients (more in OBG department).

372 patients received 2 or more units of blood/blood components, which included multiple whole blood transfusions for severely anemic patients or transfusions of fresh whole blood for the same patients, even though it was not indicated.

Out of 1453 units' blood/blood component transfused, 48 (3.30\%) units of blood developed transfusion reactions. Of these,

a. 41 were produced by whole blood, (85.41\%)

b. 5 units $(10.42 \%)$ by packed cells $\{2\}[8]$.

c. FFP 1 unit $(2.08 \%)$ for a patient with alcoholic liver disease produced reaction

- 1 unit of fresh whole blood (2.08\%) has produced reaction.
- Medical cases produced the more number of blood transfusion reactions (14 patients)

- Most of the blood transfusion reactions were allergic and most of the reactions were produced after multiple transfusions [9-12].

Most of the blood transfusion reactions were either due to storage of blood outside the blood storage cabinet i.e. refrigerators at various departments or storing at room temperature for long time. Blood issue and starting of blood transfusion time interval was greater than 6 to $8 \mathrm{hrs}$. If blood is stored at room temperature for more than $2 \mathrm{hrs}$ it starts haemolysing [13-16] \& if blood stored for more than $1 / 2$ hour at room temperature leads to proliferation of bacteria [17], which in turn produced transfusion reactions.

To prevent these reactions blood should be taken from the blood bank only when it is necessary [18].

\section{Results and Observations}

More number of patients in the age group of 26 to 45 , all these were young and adult age, in females, most cases were due to department of OBG (Table 1).

'O' Positive being predominant group for blood transfusion which corresponded to \% of blood group distribution in India. Rare blood group transfusions were also noticed (Table 2).

Whole blood is mainly used for blood transfusion, component usage is less. Component usage should be increased to prevent the transfusion reactions. Fresh whole blood indication can also be minimized, as there are 2 indications for fresh whole blood, neonates and massive blood loss (Table 3 \& 4 ).

Pre-transfusion $\mathrm{Hb} \%>10 \%$ are more in this group which is not an indication for blood transfusion, since $(<7 \mathrm{gms} \%)$ is an indication for blood transfusion (Table 5).

\begin{tabular}{|c|c|c|c|c|c|}
\hline \multirow{2}{*}{$\begin{array}{c}\text { Age in } \\
\text { Years }\end{array}$} & \multicolumn{2}{|c|}{ Males } & \multicolumn{2}{c|}{ Females } & \multirow{2}{*}{ Total } \\
\cline { 2 - 5 } & Number & $\%$ & Number & $\%$ & \\
\hline$<1$ & 29 & 9.63 & 13 & 3.29 & 42 \\
\hline $1-5$ & 5 & 1.66 & 1 & 0.25 & 6 \\
\hline $6-15$ & 7 & 2.33 & 5 & 3.03 & 12 \\
\hline $16-25$ & 23 & 7.64 & 64 & 16.2 & 87 \\
\hline $26-35$ & 44 & 14.62 & 64 & 16.2 & 108 \\
\hline $36-45$ & 42 & 13.95 & 118 & 29.87 & 160 \\
\hline $46-55$ & 55 & 18.27 & 72 & 18.22 & 127 \\
\hline $56-65$ & 51 & 16.94 & 21 & 5.32 & 72 \\
\hline $66-75$ & 26 & 8.63 & 24 & 6.07 & 50 \\
\hline$>76$ & 19 & 6.31 & 13 & 3.29 & 32 \\
\hline TOTAL & $\mathbf{3 0 1}$ & $\mathbf{1 0 0}$ & $\mathbf{3 9 5}$ & $\mathbf{1 0 0}$ & $\mathbf{6 9 6}$ \\
\hline
\end{tabular}

Table 1: Distribution of Cases according to Age and Sex.

\begin{tabular}{|c|c|c|}
\hline Blood Groups & Number & $\%$ \\
\hline A +ve & 303 & 20.86 \\
\hline B +ve & 388 & 26.7 \\
\hline AB +ve & 84 & 5.78 \\
\hline O +ve & 589 & 40.54 \\
\hline A Negative & 22 & 1.51 \\
\hline B Negative & 17 & 1.17 \\
\hline AB Negative & 10 & 0.68 \\
\hline O Negative & 40 & 2.75 \\
\hline TOTAL & 1453 & 100 \\
\hline
\end{tabular}

Table 2: Distribution of Blood Units according to Blood Groups. 
Citation: Venkatachalapathy TS (2012) A Prospective Audit of Blood Transfusion Reactions in Tertiary Care Hospital for the Use of Blood and Blood Components. J Blood Disord Transfus 3:118. doi:10.4172/2155-9864.1000118

Page 3 of 5

\begin{tabular}{|l|c|c|c|c|c|c|}
\hline $\begin{array}{l}\text { Depart- } \\
\text { ment }\end{array}$ & $\begin{array}{l}\text { Number of } \\
\text { In Patients }\end{array}$ & $\begin{array}{l}\text { Number of Patients } \\
\text { received Blood Trans- } \\
\text { fusion }\end{array}$ & $\begin{array}{l}\text { Number of } \\
\text { units trans- } \\
\text { Male }\end{array}$ & $\begin{array}{l}\text { Female } \\
\text { fused }\end{array}$ & $\begin{array}{l}\text { Total } \\
\text { received }\end{array}$ & $\begin{array}{l}\text { of Patients } \\
\text { rlood Trans- } \\
\text { fusion }\end{array}$ \\
\hline Medicine & 1516 & 81 & 82 & 163 & 452 & 10.76 \\
\hline Surgery & 1380 & 123 & 68 & 191 & 391 & 13.84 \\
\hline OBG & 1190 & 0 & 188 & 188 & 329 & 15.79 \\
\hline $\begin{array}{l}\text { Orthope- } \\
\text { dics }\end{array}$ & 463 & 60 & 41 & 101 & 188 & 21.81 \\
\hline $\begin{array}{l}\text { NICU/Pe- } \\
\text { diatrics }\end{array}$ & 885 & 36 & 16 & 52 & 92 & 5.87 \\
\hline Psychiatry & 98 & 1 & 0 & 1 & 1 & 1.02 \\
\hline TOTAL & $\mathbf{5 5 3 2}$ & $\mathbf{3 0 1}$ & $\mathbf{3 9 5}$ & $\mathbf{6 9 6}$ & $\mathbf{1 4 5 3}$ & $\mathbf{1 2 . 5 8}$ \\
\hline
\end{tabular}

Table 3: Distribution of Patients according to Departments.

\begin{tabular}{|l|c|c|}
\hline Type of Blood & Number & \% \\
\hline Whole Blood & 1106 & 76.11 \\
\hline FFP & 125 & 8.6 \\
\hline Packed Cells & 171 & 11.77 \\
\hline Platelet concentrate & 13 & 0.89 \\
\hline Fresh Whole Blood & 38 & 2.62 \\
\hline TOTAL & 1453 & 100 \\
\hline TOTAL & $\mathbf{5 5 3 2}$ & $\mathbf{1 4 5 3}$ \\
\hline
\end{tabular}

Table 4: Distribution of Type of Blood/Blood Component used for Transfusion.

\begin{tabular}{|l|c|c|c|c|c|c|}
\hline \multirow{2}{*}{ Pre-transfusion Hb\% } & \multicolumn{7}{|c|}{ Duration in Days } \\
\cline { 2 - 7 } & 0 & 1 & 2 & 3 & 4 & Total \\
\hline$>10$ & 0 & 338 & 0 & 0 & 0 & 338 \\
\hline $8-10$ & 0 & 133 & 0 & 0 & 0 & 133 \\
\hline $6-8$ & 0 & 109 & 0 & 0 & 0 & 109 \\
\hline $4-6$ & 0 & 65 & 0 & 0 & 0 & 65 \\
\hline$<4$ & 0 & 21 & 0 & 0 & 0 & 21 \\
\hline Not Investigated & $\mathbf{0}$ & $\mathbf{3 0}$ & $\mathbf{0}$ & $\mathbf{0}$ & $\mathbf{0}$ & $\mathbf{3 0}$ \\
\hline TOTAL & $\mathbf{0}$ & $\mathbf{6 9 6}$ & $\mathbf{0}$ & $\mathbf{0}$ & $\mathbf{0}$ & $\mathbf{6 9 6}$ \\
\hline
\end{tabular}

Table 5: Distribution of Pre-transfusion Hemoglobin Percentage investigated among Patients.

Whole blood transfusion should be over by 4 hrs. But in the study, prolonged duration of transfusion $>10$ hours is present (Table 6).

Recommended: Packed Cell in 2 hour, FFP in 2 hours and Platelet concentrate $-1 / 2$ hour.

In medical wards, 163 patients received 452 units of blood/ blood components transfusion. An average of 2.77 units of blood was transfused/patient. 127 patients were investigated with hematocrit [77.91\%], which is being used as transfusion trigger.

The mean pre transfusion $\mathrm{Hb} \%$ was $6 \mathrm{gms} \% \pm 3 \mathrm{gms} \%$. During the study period, $80 \%$ of the patients were suffering from chronic anemia. In medicine department transfusion trigger for a chronic anemic patient is 6.1 to $8 \mathrm{gms} \%$. These anemic patients tolerate the low $\mathrm{Hb} \%$ without cardiovascular compromise. $60 \%$ of these patients got whole blood transfusion.

272 out of 452 units of blood/blood components transfused were whole blood [59.99\%], 94 units were packed RBC's.12 units were platelet concentrate for 3 patients suffering from Dengue fever and viral hepatitis.

For chronic anemic patients, more aggressive treatment with hematinic, or where indicated usage of components would help, to reduce the transfusion reactions.

125 patients were investigated with peripheral blood smear
[76.68\%], most of the chronic anemia patients had dimorphic anemia blood picture.

$8.58 \%$ of patients ended with transfusion reactions with whole blood being the common agent for transfusion reactions \& packed cells prepared by crude method also produced reactions. The transfusion was done for the patients with $\mathrm{Hb} \%$ ranging from $1.5 \mathrm{gms} \%$ to 16.5 gms\%.

In surgical patients blood transfusion was done for chronic anemia, blood loss during surgery, hematemesis. In patients undergoing surgery, the transfusion trigger being amount of blood loss during the surgical procedure. In chronic anemic patients the transfusion trigger was clinical symptoms \& signs of anemia \& Hb\%/hematocrit. The transfusion was done for the patients with $\mathrm{Hb} \%$ ranging from $4.3 \mathrm{gms} \%$ to $18.3 \mathrm{Gms} \%$.

- 191 patients were transfused with 391 units of blood/blood components.

- 342 units of whole blood were used for transfusion.

- 36 units of packed cells.

1 unit of platelet concentrate was used for a patient suffering from thrombocytopenia.

Hematocrit was used as transfusion trigger in 137 patients [71.72\%]. Only 37 patients were investigated for peripheral blood smear [19.37\%]. Most of the chronic anemia patients were without any failure symptoms, who would have been better treated by parenteral hematinics.

Blood transfusion was used as an agent for wound healing, this is no longer practiced now-a-days, since blood transfusion will suppress the immune function \& reduce the wound healing.

The wound healing depends on the $\mathrm{PO}_{2}$ rather than on the total oxygen content of blood. Blood transfusion will only increase the total $\mathrm{O}_{2}$ content and not $\mathrm{PO}_{2}$. Looking at the time of transfusion in most of the surgical patients, transfusion was done in the postoperative period, which depended on the amount of blood loss during surgery (Table 7).

Looking at the time of transfusion, most of the transfusions were post-operative [51.56\%], most of these were single unit transfusions, noting the intra operative blood loss. $13.04 \%$ of the patients received

\begin{tabular}{|l|c|c|}
\hline Time Duration (Hrs.) & Number & $\%$ \\
\hline$<4$ & 474 & 32.62 \\
\hline $4-5$ & 536 & 36.89 \\
\hline $5-6$ & 220 & 15.14 \\
\hline $6-7$ & 108 & 7.43 \\
\hline $7-8$ & 54 & 3.71 \\
\hline $8-9$ & 12 & 0.82 \\
\hline $9-10$ & 10 & 0.68 \\
\hline$>10$ & 4 & 0.27 \\
\hline Not Available & 35 & 2.5 \\
\hline TOTAL & $\mathbf{1 4 5 3}$ & 100 \\
\hline
\end{tabular}

Table 6: Distribution of Duration of Completion of Blood/Blood Components Trans fusion.

\begin{tabular}{|l|c|c|}
\hline & Number & $\%$ \\
\hline Pre-operative & 274 & 35.4 \\
\hline Intra-operative & 101 & 13.04 \\
\hline Post-operative & 399 & 51.56 \\
\hline TOTAL & $\mathbf{7 7 4}$ & $\mathbf{1 0 0}$ \\
\hline
\end{tabular}

Table 7: Distribution of Surgical Patients Based on Time of Transfusion. 
Citation: Venkatachalapathy TS (2012) A Prospective Audit of Blood Transfusion Reactions in Tertiary Care Hospital for the Use of Blood and Blood Components. J Blood Disord Transfus 3:118. doi:10.4172/2155-9864.1000118

Page 4 of 5

blood transfusion during the surgery [indicating blood loss during surgery], which corresponded to emergency requisitions sent to blood bank.

In orthopedic wards 101 patients were transfused with 188 units of blood/blood components. Most of the transfusions were used for the managements of lower limb fractures \& spinal surgeries. The transfusion trigger for the orthopedic cases was intraoperative blood loss. $\mathrm{Hb} \%$ \& hematocrit was not used as transfusion triggers. The range of $\mathrm{Hb} \%$ in these patients was found to be $4.9 \mathrm{gms} \%$ to $17.5 \mathrm{gms} \%$. Out of 101 cases, only 82 patients were investigated with hematocrit; most of the transfusions were single unit, during postoperative period.

Only 5 out of 101 patients were investigated with peripheral smear, $80 \%$ of the patients had $\mathrm{Hb} \%$ greater than $10 \mathrm{gms} \%$. Patients with chronic anemia who are to stay for a prolonged period are better treated with hematinics.

Since most of the units of blood being inappropriately used were from the Department of Orthopedics, proper methods of reserving the blood should be practiced, blood should be taken when it is necessary. 8 units of blood produced the transfusion reactions; whole blood was the main cause.

Colloids \& crystalloids can be used aggressively during surgery to compensate for the blood loss during surgery.

In OBG ward, 188 patients were transfused with 329 units of blood /blood components, at an average of 1.75 units/patient. Out of 188 patients, 142 patients were investigated with hematocrit, which was used as transfusion trigger (75.63\%). 50\% of these patients had $\mathrm{Hb} \%$ greater than $10 \mathrm{gms} \%$. Most of the transfusions were single unit during post-operative period depending upon the intra operative blood loss.

61 patients $(33.7 \%)$ were investigated with peripheral smear, most of them had dimorphic anemia, which can be aggressively treated with hematinics. 67 patients out of 188 suffered from chronic anemia, secondary to DUB, post-menopausal bleeding and nutritional anemia.

The range of $\mathrm{Hb} \%$ in these patients was from $3.5 \mathrm{gms} \%$ to $15 \mathrm{gms} \%$. The single unit of blood used inappropriately, can be prevented by sending blood sample for grouping, cross matching and reserving the blood. Significant number of cases of emergency requisition of blood for ectopic pregnancy, APH, PPH, LSCS was also seen. 7 units of blood produced transfusion reactions (16.67\%). Usage of blood components for chronic anemic patients would be a better option.

A total of 52 patients received 92 units of blood/blood components at an average of 1.76 units/patient.

Out of 52 patients, 37 patients were investigated with hematocrit, which was used as transfusion trigger. 27 patients were investigated with peripheral smear, most of them showing normocytic normochromic blood picture, some hemolytic and some microcytic hypochromic.

Plasma was more commonly used in NICU wards for pre-term/ IUGR/septicemia/RDS.

\begin{tabular}{|l|c|c|}
\hline \multicolumn{1}{|c|}{ Type } & Number & $\%$ \\
\hline Febrile & 21 & 43.75 \\
\hline Allergic/Anaphylactic & 24 & 50 \\
\hline Acute Hemolytic & 0 & 0 \\
\hline Others & 3 & 6.25 \\
\hline TOTAL & $\mathbf{4 8}$ & $\mathbf{1 0 0}$ \\
\hline
\end{tabular}

Table 8: Distribution of Adverse Transfusion Reactions.

\begin{tabular}{|l|c|c|}
\hline \multicolumn{1}{|c|}{ Type } & Number & \% \\
\hline Emergency & 152 & 10.46 \\
\hline Routine & 1300 & 89.48 \\
\hline NA & 1 & 0.06 \\
\hline TOTAL & $\mathbf{1 4 5 3}$ & $\mathbf{1 0 0}$ \\
\hline
\end{tabular}

Table 9: Distribution of Classification of Requisitions obtained from Questionnaire.

- 3 patients received exchange transfusion.

- 4 children with thalassemia received packed cells.

\section{Analysis of Blood Transfusion Reactions}

Whole blood is the main cause for transfusion reaction since it contains all unnecessary components to a particular patient, which produces allogenic immunization in the patient. Packed cells prepared by crude method has produced reaction, don't forget even fresh whole blood has also produced reaction (Table 8 ).

Most of the requisitions are routine and emergency requisitions were almost corresponding to emergency requisitions of blood during intraoperative period. One patient with $\mathrm{Hb} \%>17.5 \mathrm{gm} \%$ was transfused with 2 units of blood, his intraoperative status was good (Table 9).

This is almost converse of above table. All requisitions were written as "emergency" even though blood was required 2 days after the day of requisition.

\section{Conclusion}

There is lack of blood transfusion committee in IGGGH\&PGI, Puducherry Hospital, which has produced inappropriate transfusions due to absence of strict transfusion triggers.

Transfusion Trigger: $\mathrm{Hb} \%<7$ gms\% is an indication for blood transfusion and hematocrit $<27 \%$ is an indication. Even though $50 \%$ of patients had $\mathrm{Hb} \%>10$ gms\% received blood transfusion, all the departments have equal distribution of hematocrit investigated, but is not used as transfusion trigger. Single unit of blood is more commonly used (324 patients) which can be prevented by sending blood for grouping, cross matching, reserving of blood, which will prevent inappropriate transfusions and wastage of blood. In surgical patients blood transfusion done mainly during the postoperative period (52\%), indicating the transfusion trigger, depended on blood loss during surgery, since $>30 \%$ blood loss during surgery is an indication for transfusion.

Blood transfusion should be started immediately after its issue from blood bank, if not used within $1 / 2$ hour, if not replace it to blood bank for cold chain maintenance.

Transfusion reactions (3.3\%) more common agent is whole blood, since it contains all unnecessary components, which produces allo immunization.

Blood component usage should be increased which will reduce the incidence of transfusion reactions.

\section{References}

1. Aubuchnon JP, Kruskall MS (1997) Transfusion safety: Realigning efforts with risks. Transfusion 37: 1211-1216.

2. Mazzei CA, Popovsky MA, Kopko PM (2008) Noninfectious complications of blood transfusion. Technical manual. (16thedn), American Association of Blood Banks, Maryland.

3. Moore SB, Taswell HF, Pineda AA, Sonnenberg CL (1980) Delayed hemolytic transfusion reactions: Evidence of the need for an improved pretransfusion compatibility test. Am J Clin Path 74: 94-97. 
Citation: Venkatachalapathy TS (2012) A Prospective Audit of Blood Transfusion Reactions in Tertiary Care Hospital for the Use of Blood and Blood Components. J Blood Disord Transfus 3:118. doi:10.4172/2155-9864.1000118

Page 5 of 5

4. Robillard P, Karl Itaj N (2002) Incidence of adverse transfusion reactions in the Quebec Hemovigilance System. Vox Sang 83: 120

5. Lichtiger B, Perry-Thornton E (1984) Hemolytic transfusion reactions in oncology patients: Experience in a large cancer center. J Clin Oncol 2: 438-442.

6. Heddle NM, Blajchman MA, Meyer RM, Lipton JH, Walker IR, et al. (2002) A randomized controlled trial comparing the frequency of acute reactions to plasma-removed platelets and prestorage WBC-reduced platelets. Transfusion 42: $556-566$.

7. NIH consensus conference (1988) Perioperative red cell transfusion. JAMA 260: $2700-2703$

8. Heddle NM, Klama LN, Griffith L, Roberts R, Shukla G, et al. (1993) A prospective study to identify risk factors associated with acute reactions to platelet and red cell transfusions. Transfusion 33: 794-797.

9. Ulhman EJ, Isgrigs E, Wallhermanfechtel M, Goodnough LT (2001) Prestorage universal WBC reduction of RBC units does not affect the incidence of transfusion reactions. Transfusion 41: 997-1000.

10. Kleinman S, Chan P, Robillard P (2003) Risk associated with transfusion of cellular blood component in Canada. Transfus Med Rev 17: 120-162.
11. Tanz WS, King KE, Ness PM (2001) Re-evaluation of transfusion reaction rates associated with leukocyte-reduced red blood cells. Transfusion 41: 7S.

12. Domen RE, Heoltage GA (2003) Allergic transfusion reactions. Arch Path Lab Med 127: 316-320.

13. Sazama K (1994) Bacteria in blood for transfusion. A review. Arch Path Lab Med 118: 350-365

14. Kuehner MJ, Roth VR, Haley NR, Gregory KR, Elder KV, et al. (2001) Transfusion-transmitted bacterial infection in the United States, 1998 through 2000. Transfusion 41: 1493-1499.

15. Popovsky MA, Taswell RF (2002) Circulatory overload: An underdiagnosed consequence of transfusion. Vox Sang 83: 469.

16. Webert KE, Blajchman MA (2003) Transfusion-related acute lung injury Transfus Med Rev 17: 252-262.

17. Sharma RR, Bhattacharya P, Thakral B, Saluja K, Marwaha N (2009) Transfusion related acute lung injury. Indian J Pathol Microbiol 52: 561-563.

18. Bhattacharya P, Marwaha N, Dhawan HK, Roy P, Sharma RR (2011) Transfusion-related adverse events at the tertiary care center in North India: An institutional hemovigilance effort. Asian J Transfus Sci 5: 164-170. 